\title{
Dynamic Splitting Experimental Study on Sandstone at Actual High Temperatures under Different Loading Rates
}

\author{
Qi Ping $\mathbb{D}^{1,2,3}$ Mingjing $W{ }^{2,3}$ Pu Yuan, ${ }^{1,2,3,4}$ Haipeng Su, ${ }^{2,3}$ and Huan Zhang ${ }^{2,3}$ \\ ${ }^{1}$ State Key Laboratory of Mining Response and Disaster Prevention and Control in Deep Coal Mines, \\ Anhui University of Science and Technology, Huainan, Anhui 232001, China \\ ${ }^{2}$ Engineering Research Center of Mine Underground Projects, Ministry of Education, Anhui University of Science and Technology, \\ Huainan, Anhui 232001, China \\ ${ }^{3}$ School of Civil Engineering and Architecture, Anhui University of Science and Technology, Huainan, Anhui 232001, China \\ ${ }^{4}$ Department of Civil, Construction, and Environmental Engineering, The University of Alabama, Tuscaloosa, AL 35487, USA
}

Correspondence should be addressed to Qi Ping; ahpingqi@163.com

Received 17 April 2020; Revised 29 May 2020; Accepted 6 June 2020; Published 22 June 2020

Academic Editor: Hongwei Yang

Copyright (C) 2020 Qi Ping et al. This is an open access article distributed under the Creative Commons Attribution License, which permits unrestricted use, distribution, and reproduction in any medium, provided the original work is properly cited.

\begin{abstract}
The tensile failure of rocks is a common failure mode in rock engineering. Many studies have been conducted on the tensile strength and failure mode of rocks after high-temperature treatment under dynamic loading. However, research on the effects of high temperature on the dynamic splitting tensile characteristics of sandstone at actual high temperatures is lacking. To investigate the dynamic tensile characteristics of rocks at actual high temperatures, split Hopkinson pressure bar (SHPB) test apparatus and high-temperature environment box were used to perform dynamic splitting tensile tests under six striker velocities for sandstone specimens at $25^{\circ} \mathrm{C}-800^{\circ} \mathrm{C}$. The dynamic splitting tensile strength, radial strain, average strain rate, and failure mode of sandstone under different test conditions were investigated. Test results revealed that the brittleness of sandstone specimens is enhanced at $200^{\circ} \mathrm{C}$ and $400^{\circ} \mathrm{C}$, but slight ductility is observed at $600^{\circ} \mathrm{C}$ and $800^{\circ} \mathrm{C}$. The strain rate effect of dynamic tensile strength is closely related to temperature. When the striker velocity exceeds $2.3 \mathrm{~m} / \mathrm{s}$, the dynamic radial strain first decreases and then increases with rising temperature. A quadratic polynomial relationship between the dynamic radial strain and temperature was observed. The temperature effect on the average strain rate is strong at low striker velocity and weak at high striker velocity. In the dynamic splitting tensile tests, high-temperature sandstone specimens are split into two semicylinders along the radial loading direction.
\end{abstract}

\section{Introduction}

In rock engineering, rock mass lies in a certain hydrogeological environment. Rock engineering under unfavorable hydrogeological condition may lead to some engineering geology disaster, such as rockburst hazard [1-3], large deformation, and water inrush hazard $[4,5]$. The temperature of rock mass rises with increasing depth, and secondary disasters may be induced in rock mass due to high geothermal situation [6]. Rock mass in deep engineering, such as superdeep mining, deep disposal of high-level radioactive nuclear wastes, geothermal resource exploitation, and underground coal gasification, always suffers from high geothermal effect $[7,8]$. The influence of high geotherm on rock mechanical characteristics has become a research hotspot in rock mechanics $[9,10]$.

Tensile strength is a significant parameter in the design of geotechnical engineering [11, 12]. Given that rock is a quasibrittle material, directly measuring its tensile strength is very difficult. In 1978, the International Society for Rock Mechanics and Rock Engineering suggested Brazilian disc test, an indirect measuring method, as a method for determining the tensile strength of rock material [13]. As tensile strength of rocks is only approximately one-tenth less than its compressive strength, the deformation and failure mode of rock mass mainly depend on its tensile characteristics [14]. Research on the quasistatic or dynamic splitting tensile tests of rocks is mainly conducted at room 
temperature or after heat treatment. These achievements contribute to understanding the tensile strength and deformation properties of rocks under test conditions. However, studies on dynamic splitting tensile tests at real-time high temperature are rarely reported $[15,16]$. As rock mass exists in a coupled high-temperature and dynamic-stress environment, high geothermal condition and dynamicstress disturbance increase the possibility of engineering hazards. Hence, studying the dynamic tensile strength of rocks under coupled high temperature and high loading rate can provide experimental references for the stability analysis of surrounding rocks in blasting excavation process.

The results of several studies indicate that temperature has a significant influence on the physical and mechanical properties of rocks [17-19]. Much literature has recently emerged and offers contradictory findings about the compressive and tensile strengths of rocks after temperature treatment. The action mechanism of temperature on the internal structure of rocks has also been investigated. Studies reveal that, in high-temperature situations, thermal cracking occurs and leads to the deterioration of the properties of rocks, such as porosity, Young's modulus, and mechanical strength [17]. By using MTS815 servo-controlled rock mechanics testing system, Chen et al. [17] conducted Brazilian splitting tests for sandstone specimens, which were heated to six kinds of temperatures ranging from $25^{\circ} \mathrm{C}$ to $1000^{\circ} \mathrm{C}$ and then cooled down to room temperature naturally, to investigate the damage evolution caused by high temperature. By varying temperatures and duration of thermal treatment, Sirdesai et al. [16] performed indirect tensile test by using a Brazilian cage. The tensile strength and the physical characteristics of the rocks underwent a substantial and irreversible change upon heating. After heat treatment from $100^{\circ} \mathrm{C}$ to $600^{\circ} \mathrm{C}$, Liang et al. [19] compared the physical properties and longitudinal wave velocities of two cooling ways, natural and water cooling. They also studied the Brazilian splitting characteristics. The above experiments were conducted under static or quasistatic load, and the effects of temperature and rock type on static tensile strength were investigated. However, strain rate effect was not considered.

The deformation and failure of rocks under dynamic loads, such as blasting load, are closely related to loading rate, which shows a distinct strain rate effect $[20,21]$. Spalling test based on Hopkinson bar apparatus is a method for determining the tensile strength of concrete at high strain rates. Klepaczko and Brara [22] conducted dynamic tensile test for concrete, and the dynamic tensile strength was determined by spalling caused by reflected tensile wave. Using a Hopkinson bar apparatus, Schuler et al. [23] investigated the dynamic tensile and fracture energy of concrete at high strain rates by measuring the free surface velocity at the end of the specimen. For the complexity of the time and space of the transient loading in spalling tests, Erzar and Forquin [24] put forward several advances to improve the process of spalling tests. Given its simple test design and operation process, the Brazilian splitting test in static state is performed to measure the dynamic tensile strength in the split Hopkinson pressure bar (SHPB) test [25, 26]. The
Brazilian splitting test has become a handy and effective test method for studies on dynamic tensile strength [27-29]. By conducting dynamic Brazilian splitting tests for coal specimens, Zhao et al. [30] discussed the influence of impact velocity and stratification dip angle on dynamic tensile strength, failure strain, and strain rate. Moreover, primary analyses on dynamic splitting and surface strain field evolution were conducted using high-speed camera and speckle image correlation digital technique. Through the dynamic Brazilian splitting test, $\mathrm{Du}$ et al. [31] investigated the influence of wetting-drying cycle and strain rate on the dynamic tensile strength of red sandstone and developed a calculation formula for dynamic tensile strength. Wen et al. [32] performed dynamic splitting tensile tests for sandstone specimens in various moisture contents. Li et al. [33] conducted high-strain-rate dynamic splitting tests for intact granite specimens and prefabricated single-jointed granite specimens with a height-to-diameter ratio of 0.5 . However, as all the experiments were conducted at room temperature, the major problem of this kind of test is that temperature effect is not considered.

In recent years, SHPB test with high temperature has been attempted [34-36]. Using an SHPB test system, Yin et al. [35] performed dynamic fracture tests on a cracked straight-through Brazilian disc to investigate the dynamic fracture toughness of granite after heat treatment at $25^{\circ} \mathrm{C}$ to $600^{\circ} \mathrm{C}$. Liu et al. [36] conducted dynamic tensile tests for marble Brazilian disc specimens after heat treatment at $25^{\circ} \mathrm{C}$ to $1000^{\circ} \mathrm{C}$. They also analyzed the influence of loading rate and temperature on dynamic tensile strength and failure modes by using an SHPB test system with large diameter. Most studies on the effect of temperature on the dynamic mechanical properties of rocks focus on the test conditions after temperature treatment. However, only little attention has been paid to the dynamic tensile characteristics of rocks at real-time temperatures.

In this study, dynamic splitting tensile tests under six striker velocities were conducted for sandstone specimens under five kinds of real-time temperature conditions $\left(25^{\circ} \mathrm{C}\right.$, $200^{\circ} \mathrm{C}, 400^{\circ} \mathrm{C}, 600^{\circ} \mathrm{C}$, and $800^{\circ} \mathrm{C}$ ) by using $\phi 50 \mathrm{~mm} \mathrm{SHPB}$ test apparatus and high-temperature environment box. And dynamic tensile stress-strain curves were obtained based on acquired incident wave, reflected wave, and transmitted wave. Then, the influence of high temperature on dynamic splitting tensile characteristics of sandstone was analyze from dynamic tensile strength, dynamic radial strain, average strain rate, and failure modes. The strain rate effect of high-temperature sandstone was also studied.

\section{Methodology}

2.1. Preparation of High-Temperature Sandstone Specimens. Sandstone samples were obtained from the Panyidong coal mine of Huainan Mining Group. Raw rock cores were obtained by ZS-100 vertical drilling machine with drilling direction perpendicular to the bedding plane. Then, DQ-4 cutting machine and SHM-200 double-end grinding machine were applied to process raw rock cores into disc specimens with the size of $\phi 50 \mathrm{~mm} \times 25 \mathrm{~mm}$. Both ends of 
the sandstone specimens were flat within $0.02 \mathrm{~mm}$, and irregularities across the thickness of the disc specimen were within $0.025 \mathrm{~mm}$. To reduce the difference between the rock structure and rock composition, tested sandstone specimens were obtained from one rock sample and had similar longitudinal wave velocity.

As presented in Figure 1, box-type resistance furnace with automatic temperature control system was used to heat the sandstone specimens. Its heating part is composed of silicon carbide, and its highest heating temperature is $1200^{\circ} \mathrm{C}$.

According to Wang et al. [37], the time constant to achieve a uniform temperature distribution state is $r^{2} / d$, where $r$ is the radius of rock sample and $d$ is the thermal diffusivity $d$ of the rock. In this study, the radius of sandstone specimen was $25 \mathrm{~mm}$ (namely, $0.025 \mathrm{~m}$ ), and the thermal diffusivity of sandstone ranged from $0.75 \times 10^{-6} \mathrm{~m}^{2} / \mathrm{s}$ to $1.27 \times 10^{-6} \mathrm{~m}^{2} / \mathrm{s}$. Then, the time constant for temperature equilibrium in sandstone specimens ranges from $492 \mathrm{~s}$ $(8.2 \mathrm{~min})$ to $833.3 \mathrm{~s}$ (about $13.9 \mathrm{~min}$ ). Hence, the temperature gradients in sandstone specimens are modest during heating. Sandstone specimens were heat treated at a rate of $10^{\circ} \mathrm{C} / \mathrm{min}$; then sandstone specimens were kept in the boxtype resistance furnace for $4 \mathrm{~h}$ to make the temperature effect more sufficient.

2.2. Real-Time High-Temperature SHPB Test System. As illustrated in Figure 2, real-time high-temperature SHPB test system consists of a $\phi 50 \mathrm{~mm}$ variable cross-section SHPB test apparatus and a high-temperature environment box.

All bars in the SHPB test apparatus are made of highstrength alloy steel with a density of $7580 \mathrm{~kg} / \mathrm{m}^{3}$, Young's modulus of $210 \mathrm{GPa}$, and longitudinal wave velocity of $5190 \mathrm{~m} / \mathrm{s}$. The lengths of the striker, input bar, output bar, and absorbing bar are $800,2400,1200$, and $1000 \mathrm{~mm}$, respectively. The impact end of the input bar is a $200 \mathrm{~mm}$ variable cross-section part with its diameter gradually varying from $37 \mathrm{~mm}$ to $50 \mathrm{~mm}$.

Figure 3 presents the acquired incident stress $\sigma_{\mathrm{I}}(t)$, reflected stress $\sigma_{\mathrm{R}}(t)$, and transmitted stress $\sigma_{\mathrm{T}}(t)$ for $800^{\circ} \mathrm{C}$ sandstone specimen. To estimate stress equilibrium, the stress at the end contacting with the input bar is also calculated by $\sigma_{\mathrm{I}}(t)+\sigma_{\mathrm{R}}(t)$.

As presented in Figure 3, the stress-time histories at the end contacting with input bar $\sigma_{\mathrm{I}}(t)+\sigma_{\mathrm{R}}(t)$ are basically consistent with the end contacting with output bar $\sigma_{\mathrm{T}}(t)$, which denotes that the dynamic splitting tests results are valid and reliable. Moreover, due to the variable crosssection part in the front of the input bar, $\mathrm{P}-\mathrm{C}$ oscillations were eliminated, and the increasing time of incident stress wave was retarded, which could prevent the premature failure of rock-like materials and improve the stress uniformity in the specimen [38-40].

As shown in Figure 4, a high-temperature environment box was designed and manufactured for the SHPB test apparatus. The box can provide a high-temperature environment ranging from room temperature to $1200^{\circ} \mathrm{C}$. It can compensate for the heat loss during the transfer and

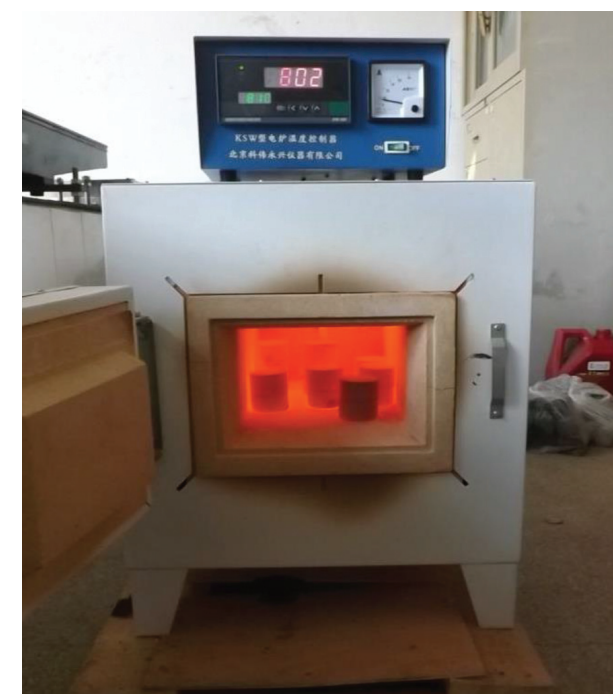

Figure 1: Sandstone specimens heated using box-type resistance furnace.

placement of high-temperature sandstone specimen and maintain the temperature during dynamic splitting tensile tests. The high-temperature box can also prevent the fragments from flying out and ensure safety during dynamic splitting tensile tests.

High-temperature environment box was equipped with a temperature controller, which can monitor the temperature with a temperature sensor and heat the sandstone specimen to the designed temperature. As shown in Figure 4, the high-temperature environment box consists of two parts, the upper and the lower parts. The lower part was set up on the girder of the SHPB test apparatus and could slide along the girder. Hinge and buckle were applied to connect and fix these two parts. When the buckle was opened, the upper part could be turned up, and high-temperature sandstone specimens could be placed and removed.

\subsection{Experimental Procedure of Dynamic Splitting Tensile Tests.} Experimental procedure of dynamic splitting tensile tests for high-temperature environment box is shown as follows:

First, place the processed sandstone specimen into the box-type resistance furnace to elevate the specimen to the designed high temperature.

Second, heat the high-temperature environment box at the designed high temperature.

Third, place the striker in a settled position in a launching chamber, and set the air pressure to drive the striker.

Fourth, take the sandstone specimen from the box-type resistance furnace to the high-temperature environment box and immediately place the sandstone between the input and output bars, as illustrated in Figure 5. The axis of the sandstone specimen should be coaxial with the input and output bars.

Fifth, lock the high-temperature environment box and immediately fill the gap between the bars and the box with fire retardant cotton. 


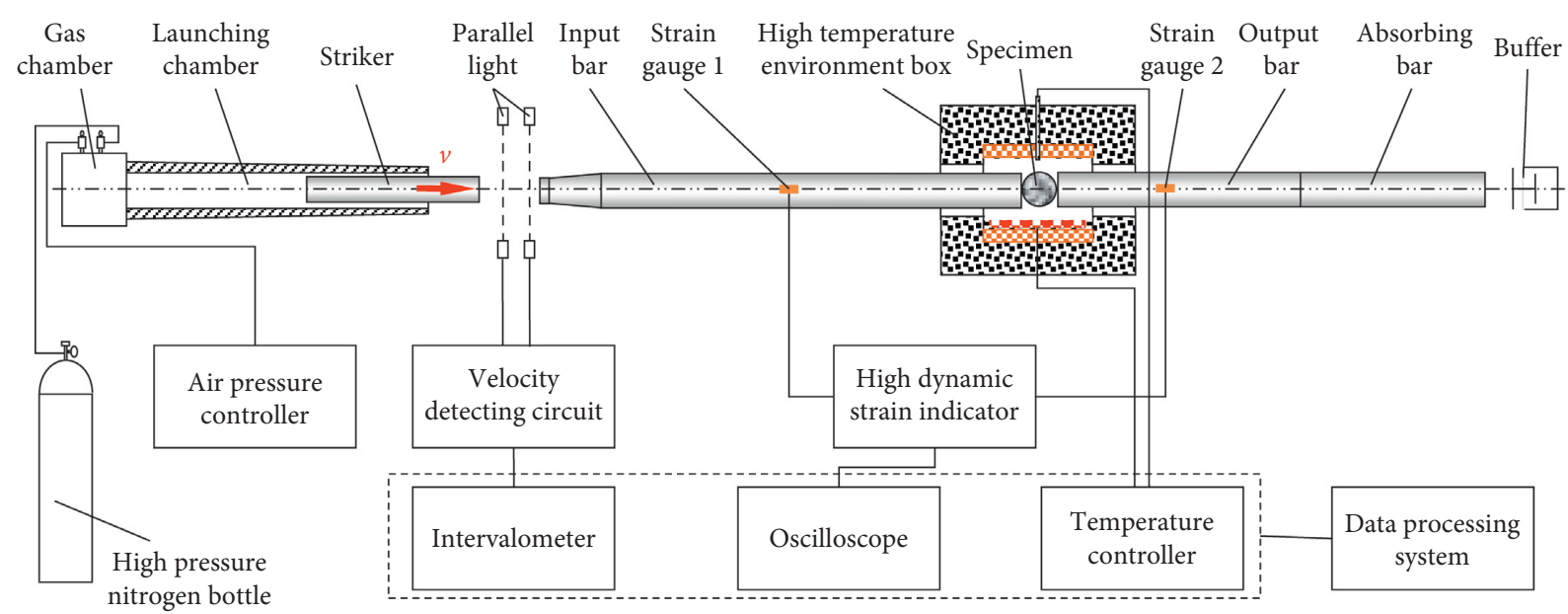

FIGURE 2: Schematic of real-time high-temperature SHPB test system.

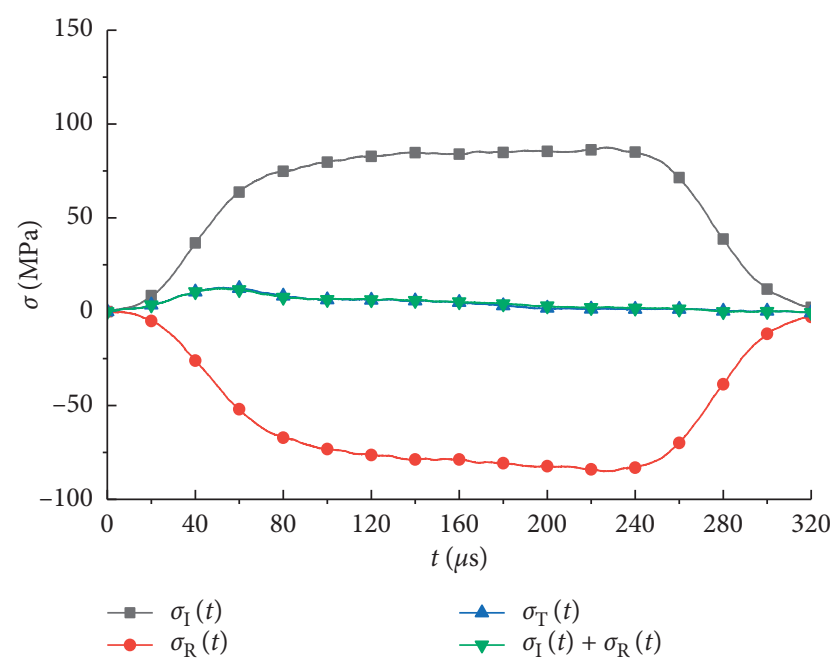

Figure 3: Acquired stress-time histories in dynamic splitting tensile tests $\left(800^{\circ} \mathrm{C}, v=5.4 \mathrm{~m} / \mathrm{s}\right)$.

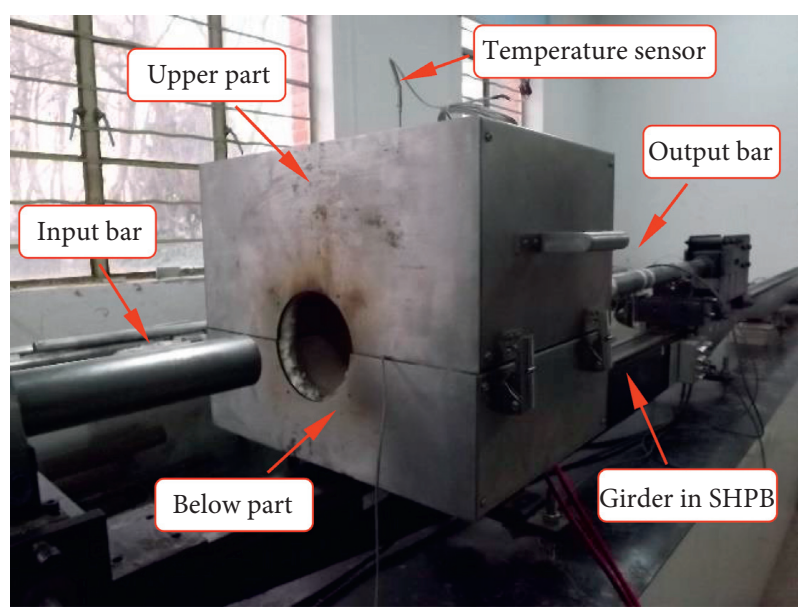

Figure 4: High-temperature environment box for SHPB test apparatus.

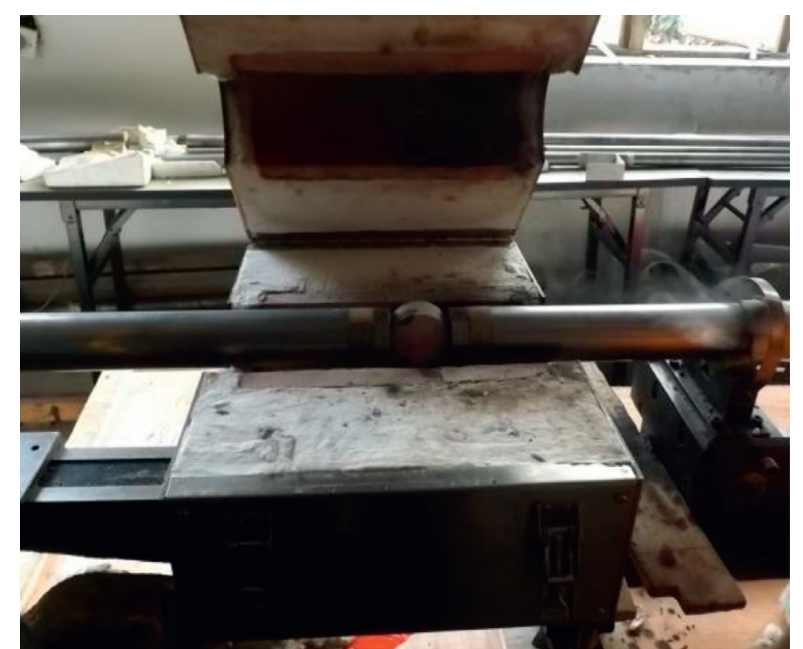

Figure 5: Placement of high-temperature sandstone specimen in the dynamic splitting tensile test.

Sixth, maintain the high temperature for $5 \mathrm{~min}$ to compensate for the heat lost during transfer and placement.

Finally, launch the striker and load the dynamic stress wave to the high-temperature sandstone specimen.

According to Xia et al. [41], the shape of the incident wave is basically unchanged when it propagates through a gradient temperature field. The uncorrected incident and transmitted wave exhibit little difference from the amplitude of the original wave at approximately $10 \%$. To eliminate the influence of high temperature on the acquired signals from the input and output bars, three countermeasures were adopted. First, the temperature of the high-temperature environment box was quickly elevated to the designed value. For example, the time for elevating to $800^{\circ} \mathrm{C}$ was not longer than $15 \mathrm{~min}$. Second, the gap between the bars and the box was filled with fire retardant cotton to avoid thermal radiation. Third, a towel soaked in cold water was twisted around the input and output bars near the high-temperature environment box to cool down and reduce heat conduction. In 
the dynamic splitting tensile test, the surface temperature on both bars was cooled down to room temperature $\left(25^{\circ} \mathrm{C}\right)$ at $320 \mathrm{~mm}$ away from the outlet of the high-temperature environment box. Hence, the strain gauges were mounted $400 \mathrm{~mm}$ away from the high-temperature environment box to eliminate the high-temperature effect.

2.4. Basic Principle of Dynamic Splitting Tensile Tests. During the dynamic splitting tensile test, the high-temperature sandstone specimen was placed between the input and output bars, as shown in Figure 6.

When launching, the striker impacts the input bar with a certain velocity $v$; then an incident wave $\varepsilon_{\mathrm{I}}(t)$ is generated in the input bar. When the incident wave propagates to the contact interface with the high-temperature sandstone specimen, some of incident waves reflect to the input bar, while the other incident waves transmit into high-temperature sandstone specimens. Reflection and transmission also occur in the contact interface between the high-temperature sandstone specimen and the output bar. The wave reflected to the input bar is called reflected wave $\varepsilon_{\mathrm{R}}(t)$, and the wave propagating into the output bar is called transmitted wave $\varepsilon_{\mathrm{T}}(t)$. Incident wave $\varepsilon_{\mathrm{I}}(t)$, reflected wave $\varepsilon_{\mathrm{R}}(t)$, and transmitted wave $\varepsilon_{\mathrm{T}}(t)$ can be collected by the strain gauges mounted on the input and output bars.

According to the two basic assumptions of SHPB tests, the dynamic force, dynamic radial strain, and strain rate of high-temperature sandstone specimen can be calculated using the following three wave methods [26]:

$$
\begin{aligned}
& P(t)=\frac{E A}{2}\left[\varepsilon_{I}(t)+\varepsilon_{R}(t)+\varepsilon_{T}(t)\right], \\
& \varepsilon(t)=\frac{C}{D} \int_{0}^{\tau}\left[\varepsilon_{I}(t)-\varepsilon_{R}(t)-\varepsilon_{T}(t)\right] \mathrm{d} t, \\
& \dot{\varepsilon}(t)=\frac{C}{D}\left[\varepsilon_{I}(t)-\varepsilon_{R}(t)-\varepsilon_{T}(t)\right],
\end{aligned}
$$

where $E$ and $A$ are Young's modulus and cross section of bar, $C$ is longitudinal wave velocity of bar, and $D$ is diameter of high-temperature sandstone specimen.

The issue on the validity of dynamic splitting tensile test is whether the tensile crack is parallel to the loading direction or not [42]. To validate the dynamic splitting tensile test, Gomez et al. [43] performed photoelastic dynamic splitting tensile tests. Photoelastic results show that the specimen quickly reaches stress equilibrium and remains in stress equilibrium until fracture occurs. Therefore, the assumption of elastic behavior is reasonable for dynamic splitting tensile test. Hence, the calculation formula in static splitting tensile test can also be used for dynamic splitting tensile test. When dynamic splitting failure occurs, the maximum dynamic tensile stress is its dynamic tensile strength. According to elastic mechanics, the dynamic tensile stress can be calculated using the following equation:

$$
\sigma_{t}^{d}(t)=\frac{2 P(t)}{\pi D H}=\frac{E A}{\pi D H}\left[\varepsilon_{I}(t)+\varepsilon_{R}(t)+\varepsilon_{T}(t)\right],
$$

where $H$ is the height of disc specimen.

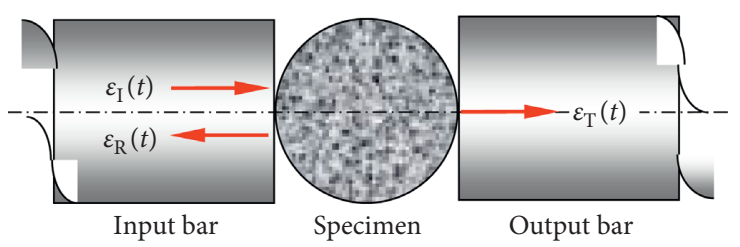

Figure 6: Principle of dynamic splitting tensile tests.

\section{Result Analysis and Discussion}

3.1. Dynamic Tensile Stress-Strain Curve. The typical dynamic tensile stress-strain curves of high-temperature sandstone specimens at temperatures ranging from $25^{\circ} \mathrm{C}$ to $800^{\circ} \mathrm{C}$ are shown in Figure 7.

As illustrated in Figure 7, when the heating temperature ranges from $25^{\circ} \mathrm{C}$ to $800^{\circ} \mathrm{C}$, the dynamic tensile stress-strain curves at various striker velocities are similar to one another at the same temperature. In addition, the peak tensile stress increases as the growth of striker velocity increases. When the temperature is $25^{\circ} \mathrm{C}$, the dynamic tensile stress-strain curves gently increase before the peak points. When the temperature is $200^{\circ} \mathrm{C}$, the dynamic tensile stress-strain curves exhibit a steep increase before the peak points, and a relatively small peak radial strain is presented. Moreover, the brittle failure characteristics of the sandstone at $200^{\circ} \mathrm{C}$ and $400^{\circ} \mathrm{C}$ are more evident than those at other temperatures. When temperature rises from $200^{\circ} \mathrm{C}$ to $800^{\circ} \mathrm{C}$, the peak radial strain shows a right shift tendency, which indicates weak brittleness. At $600^{\circ} \mathrm{C}$ and $800^{\circ} \mathrm{C}$, the sandstone specimens exhibit reduced brittleness and demonstrate slight ductility. The peak radial strains at $800^{\circ} \mathrm{C}$ remain larger than those at $25^{\circ} \mathrm{C}$.

3.2. Strain Rate Effect of High-Temperature Sandstone. The variation of the strain rate of high-temperature sandstone specimens with striker velocity is shown in Figure 8.

As shown in Figure 8, the strain rate increases in a quadratic polynomial function as striker velocity increases:

$$
\dot{\varepsilon}=f v^{2}+g v+h,
$$

where $f, g$, and $h$ are fitting parameters and their values are listed in Table 1.

The relation between the dynamic tensile strength and average strain rate of high-temperature sandstone specimens at $25^{\circ} \mathrm{C}$ to $800^{\circ} \mathrm{C}$ is presented in Figure 9 .

As illustrated in Figure 9, the dynamic tensile strength increases as the growth of average strain rate increases under the same temperature. Hence, a distinct strain rate effect is observed. The dynamic tensile strength-average strain rate curve at $200^{\circ} \mathrm{C}$ and $400^{\circ} \mathrm{C}$ is higher than that at $25^{\circ} \mathrm{C}$. Therefore, a temperature strengthening effect is observed for dynamic tensile strength. On the contrary, dynamic tensile strength-average strain rate curve at $600^{\circ} \mathrm{C}$ and $800^{\circ} \mathrm{C}$ is lower than that at $25^{\circ} \mathrm{C}$. Hence, a temperature weakening effect is found. An approximate power relation exists between dynamic tensile strength and average strain rate, and the fitting formula is shown as follows: 


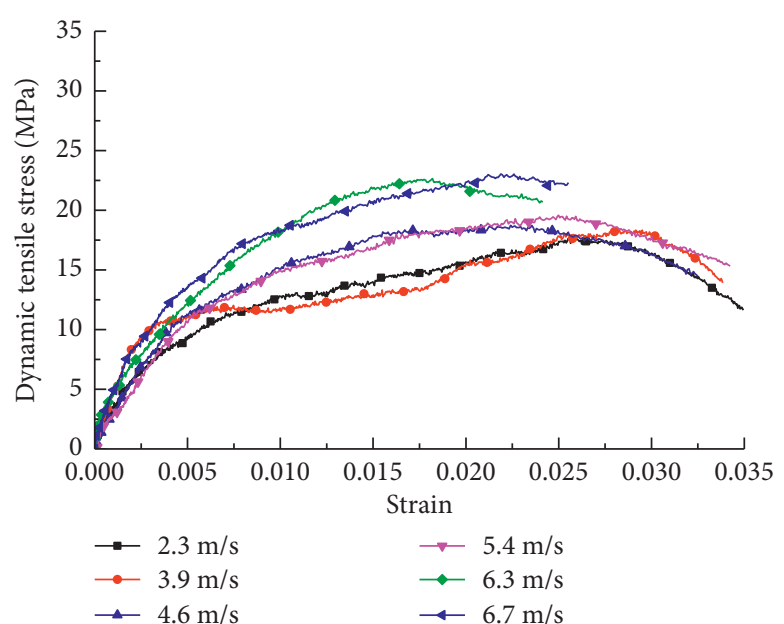

(a)

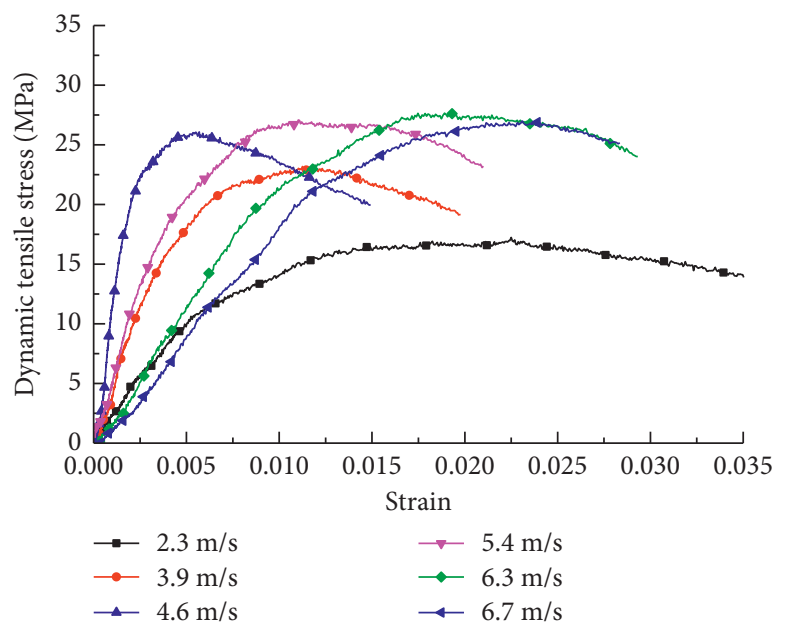

(c)

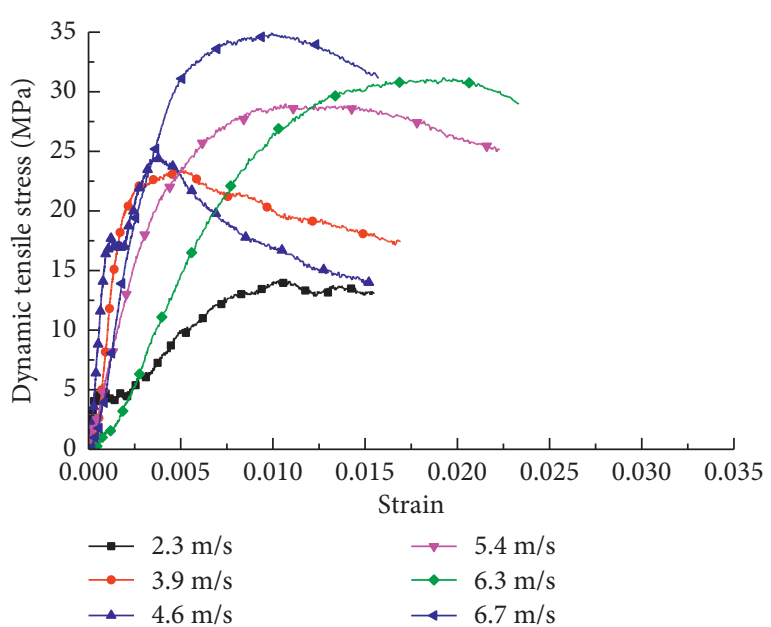

(b)

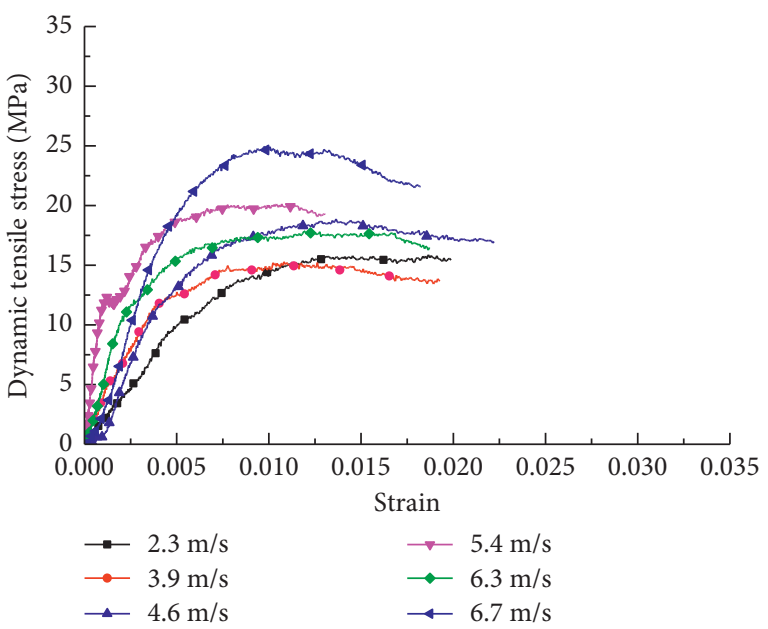

(d)

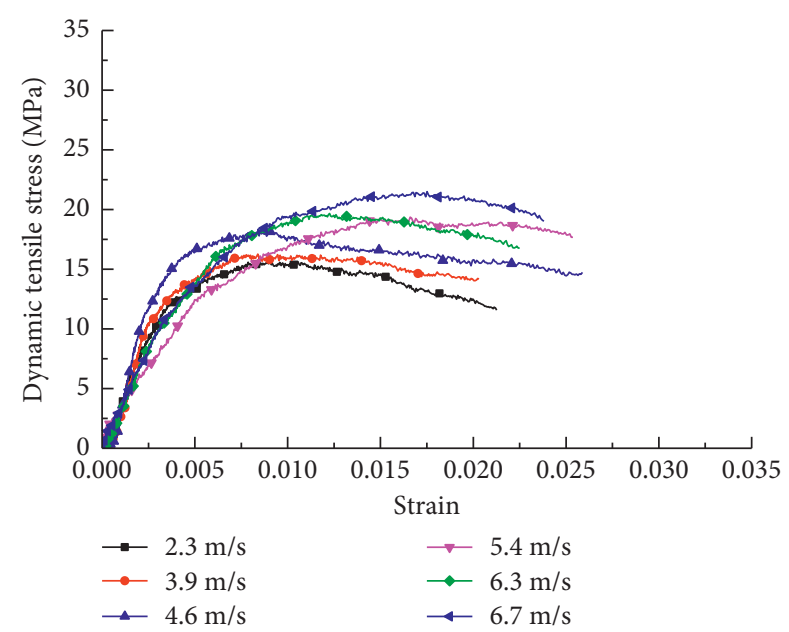

(e)

Figure 7: Dynamic tensile stress-strain curves of sandstone at various temperatures. (a) $25^{\circ} \mathrm{C}$. (b) $200^{\circ} \mathrm{C}$. (c) $400^{\circ} \mathrm{C}$. (d) $600^{\circ} \mathrm{C}$. (e) $800^{\circ} \mathrm{C}$. 


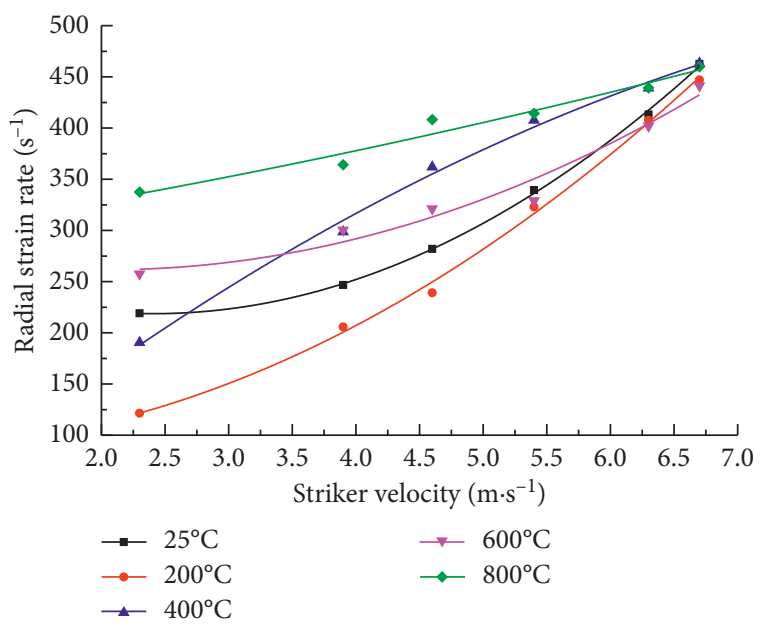

FIGURE 8: Variation of strain rate with striker velocity.

TABLE 1: Fitting parameters for strain rate and striker velocity.

\begin{tabular}{lcccc}
\hline Temperature $\left({ }^{\circ} \mathrm{C}\right)$ & $f$ & $g$ & $h$ & Correlation coefficient $\left(R^{2}\right)$ \\
\hline 25 & 13.0920 & -62.9270 & 294.270 & 0.9992 \\
200 & 8.9844 & -6.3103 & 88.581 & 0.9975 \\
400 & -4.9436 & 106.7800 & -31.475 & 0.9950 \\
600 & 7.8624 & -32.0590 & 294.230 & 0.9669 \\
800 & 1.0422 & 18.1230 & 288.660 & 0.9652 \\
\hline
\end{tabular}

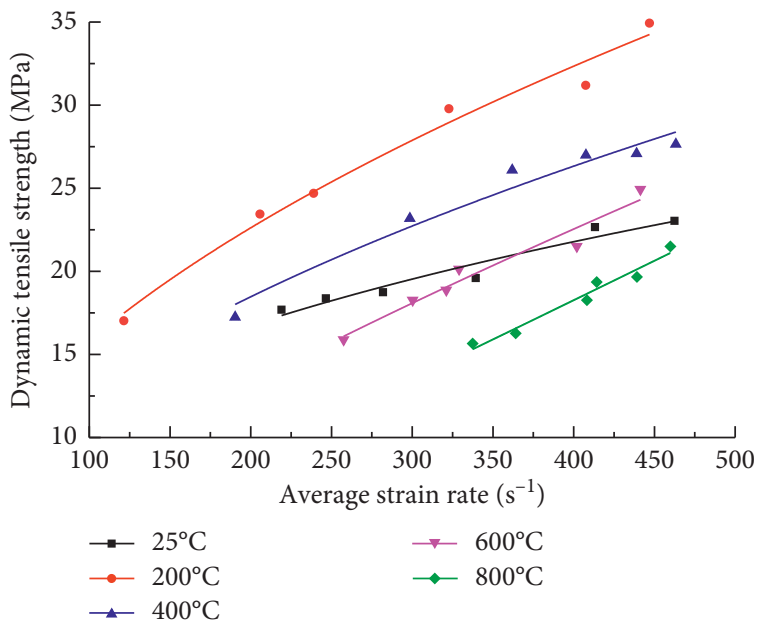

FIGURE 9: Relation between dynamic tensile strength and average strain rate.

$$
\sigma_{t}^{d}=a \dot{\varepsilon}^{b},
$$

where $\sigma_{t}^{d}$ is the dynamic tensile strength, $\dot{\varepsilon}$ is the average strain rate, and $a$ and $b$ are the fitting parameters. Their values are listed in Table 2.

As presented in Table 2, the minimum correlation coefficient is 0.9438 , which indicates a remarkable correlation. The variation of fitting parameters with heating temperature is shown in Figure 10.
TABLE 2: Fitting parameters for dynamic tensile strength and average strain rate.

\begin{tabular}{lccc}
\hline Temperature $\left({ }^{\circ} \mathrm{C}\right)$ & $a$ & $b$ & Correlation coefficient $\left(R^{2}\right)$ \\
\hline 25 & 2.3696 & 0.3699 & 0.9438 \\
200 & 1.3864 & 0.5262 & 0.9869 \\
400 & 1.0464 & 0.5387 & 0.9693 \\
600 & 0.2295 & 0.7655 & 0.9582 \\
800 & 0.0411 & 1.0175 & 0.9642 \\
\hline
\end{tabular}

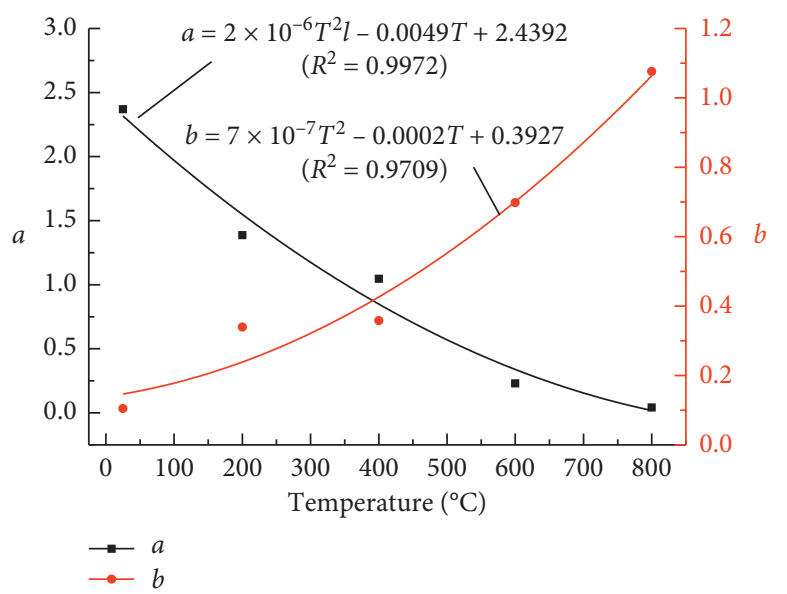

FIgURE 10: Variation of fitting parameters for dynamic tensile strength and strain rate with heating temperature. 
As displayed in Figure 10, fitting parameter $a$ decreases as temperature increases, whereas fitting parameter $b$ increases as temperature increases. A quadratic polynomial relation exists between fitting parameters $a$ and $b$ and heating temperature. Therefore, the strain rate effect of dynamic tensile strength is closely related to temperature.

\subsection{Temperature Effect on the Dynamic Tensile Strength of} High-Temperature Sandstone. The variation of the dynamic tensile strength of high-temperature sandstone specimens with heating temperature is illustrated in Figure 11.

As displayed in Figure 11, the dynamic tensile strength exhibits a decreasing tendency with the increase in heating temperature under various striker velocities. When the striker velocity is $2.3 \mathrm{~m} / \mathrm{s}$, the dynamic tensile strength at $800^{\circ} \mathrm{C}$ is approximately $12 \%$ less than that at $25^{\circ} \mathrm{C}$. When the striker velocity exceeds $2.3 \mathrm{~m} / \mathrm{s}$, the dynamic tensile strength first increases and then decreases as the heating temperature increases. The dynamic tensile strength at $200^{\circ} \mathrm{C}$ and $400^{\circ} \mathrm{C}$ is greater than that at $25^{\circ} \mathrm{C}$. Compared with the dynamic tensile strength at $25^{\circ} \mathrm{C}$, that at $200^{\circ} \mathrm{C}$ increases by approximately $28 \%, 32 \%, 52 \%, 38 \%$, and $52 \%$ at striker velocities of $3.9,4.6,5.4,6.3$, and $6.7 \mathrm{~m} / \mathrm{s}$, respectively. The dynamic tensile strength at $600^{\circ} \mathrm{C}$ is basically equal to that at $25^{\circ} \mathrm{C}$. However, the dynamic tensile strength at $800^{\circ} \mathrm{C}$ reduces by approximately $11 \%, 3 \%, 1 \%, 13 \%$, and $7 \%$ at striker velocities of $3.9,4.6,5.4,6.3$, and $6.7 \mathrm{~m} / \mathrm{s}$, respectively. Hence, the temperature strengthening effect is observed from $200^{\circ} \mathrm{C}$ to $400^{\circ} \mathrm{C}$, whereas the weakening effect is observed from $600^{\circ} \mathrm{C}$ to $800^{\circ} \mathrm{C}$. The minimum and maximum temperatures of the dynamic tensile strength are $200^{\circ} \mathrm{C}$ and $800^{\circ} \mathrm{C}$, respectively.

3.4. Temperature Effect on the Dynamic Radial Strain of HighTemperature Sandstone. The variation of the peak dynamic radial strain of the high-temperature sandstone specimens with heating temperature is shown in Figure 12.

As displayed in Figure 12, the peak dynamic radial strain exhibits a decreasing tendency as the heating temperature increases at various striker velocities. When the striker velocity is $2.3 \mathrm{~m} / \mathrm{s}$, the peak dynamic radial strain decreases as the heating temperature increases:

$$
\varepsilon=-0.0011 T^{2}+0.0031 T+0.0235,\left(R^{2}=0.9930\right) .
$$

However, when the striker velocity exceeds $2.3 \mathrm{~m} / \mathrm{s}$, the peak dynamic radial strain first decreases and then increases as the heating temperature increases. The peak dynamic radial strain rapidly reduces when the temperature rises from $25^{\circ} \mathrm{C}$ to $200^{\circ} \mathrm{C}$. It reduced by $83 \%, 80 \%, 57 \%, 40 \%$, and $18 \%$ at striker velocities of $3.9,4.6,5.4,6.3$, and $6.7 \mathrm{~m} / \mathrm{s}$, respectively. Peak dynamic radial strain gradually increased when the temperature rose from $200^{\circ} \mathrm{C}$ to $800^{\circ} \mathrm{C}$, thereby indicating a transition from brittleness to ductility. A quadratic polynomial relation exists between peak dynamic radial strain and temperature, which is expressed as follows:

$$
\varepsilon=c T^{2}+d T+e\left(200^{\circ} \mathrm{C} \leq T \leq 800^{\circ} \mathrm{C}\right),
$$

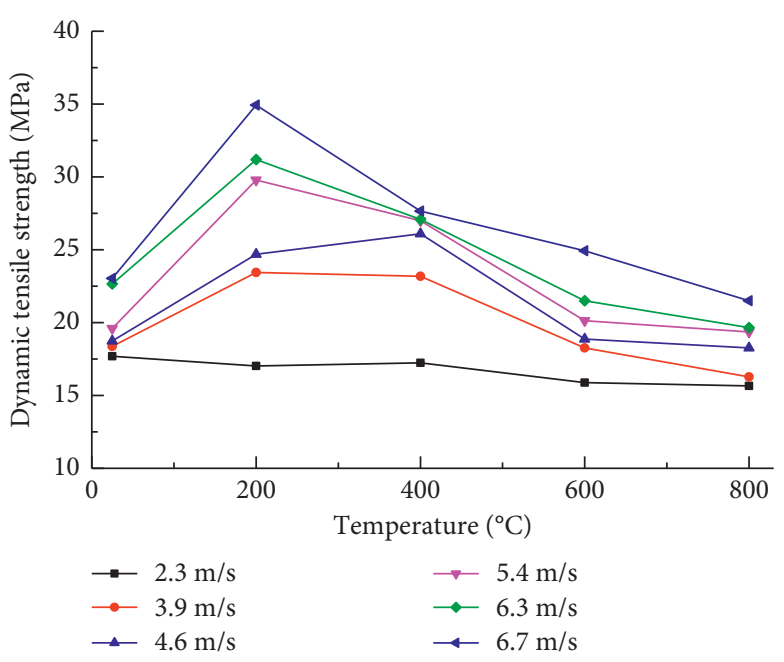

FIgURE 11: Variation of dynamic tensile strength with heating temperature.

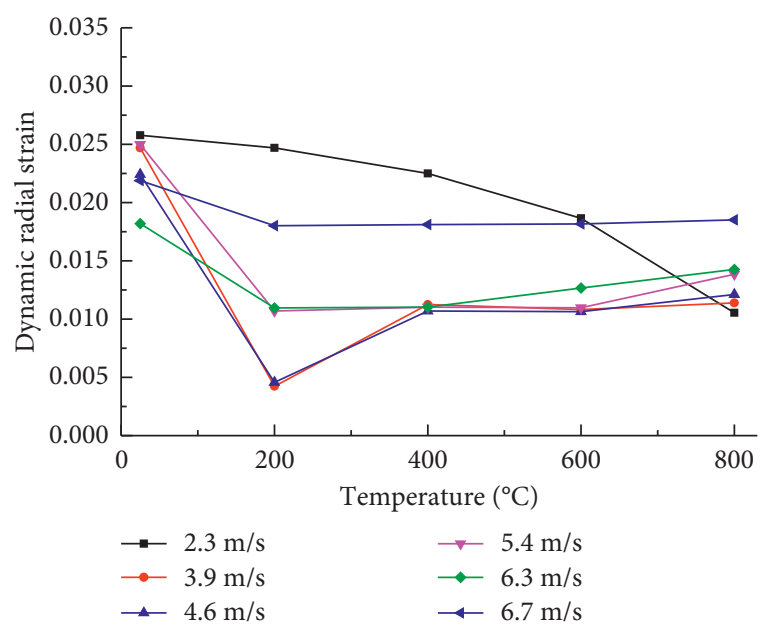

FIGURE 12: Variation of peak dynamic radial strain with heating temperature.

where $c, d$, and $e$ are the fitting parameters and their values are listed in Table 3.

3.5. Temperature Effect on the Strain Rate of High-Temperature Sandstone. The variation of the average strain rate of high-temperature sandstone specimens with heating temperature is shown in Figure 13.

Figure 13 illustrates that the average strain rate first decreases and then increases as heating temperature increases and reaches its minimum value at $200^{\circ} \mathrm{C}$. Moreover, the average strain rate-temperature curves exhibit a shift tendency as the striker velocity increases. When the striker velocity is $2.3 \mathrm{~m} / \mathrm{s}$, the average strain rate at $25^{\circ} \mathrm{C}, 200^{\circ} \mathrm{C}$, $400^{\circ} \mathrm{C}, 600^{\circ} \mathrm{C}$, and $800^{\circ} \mathrm{C}$ is $219.1 \mathrm{~s}^{-1}, 121.4 \mathrm{~s}^{-1}, 190.4 \mathrm{~s}^{-1}$, $257.5 \mathrm{~s}^{-1}$, and $337.4 \mathrm{~s}^{-1}$, respectively. When the striker velocity is $6.7 \mathrm{~m} / \mathrm{s}$, the average strain rate at $25^{\circ} \mathrm{C}, 200^{\circ} \mathrm{C}, 400^{\circ} \mathrm{C}$, $600^{\circ} \mathrm{C}$, and $800^{\circ} \mathrm{C}$ is $462.5 \mathrm{~s}^{-1}, 447 \mathrm{~s}^{-1}, 463.3 \mathrm{~s}^{-1}, 441.3 \mathrm{~s}^{-1}$, and $459.9 \mathrm{~s}^{-1}$, respectively. The variation range of the average 
TABLE 3: Fitting parameters for peak dynamic radial strain and temperature.

\begin{tabular}{lcccc}
\hline Striker velocity $\left({\left.\mathrm{m} \cdot \mathrm{s}^{-1}\right)}^{-1}\right.$ & $C$ & $d$ & $e$ & Correlation coefficient $\left(R^{2}\right)$ \\
\hline 3.9 & $-1.6 \times 10^{-3}$ & 0.0102 & 0.0039 & 0.9012 \\
4.6 & $-1.2 \times 10^{-3}$ & 0.0081 & 0.0020 & 0.9120 \\
5.4 & $6.0 \times 10^{-4}$ & 0.0022 & 0.0125 & 0.9158 \\
6.3 & $4.0 \times 10^{-4}$ & 0.0008 & 0.0113 & 0.9828 \\
6.7 & $6.0 \times 10^{-5}$ & 0.0002 & 0.0181 & 0.9650 \\
\hline
\end{tabular}

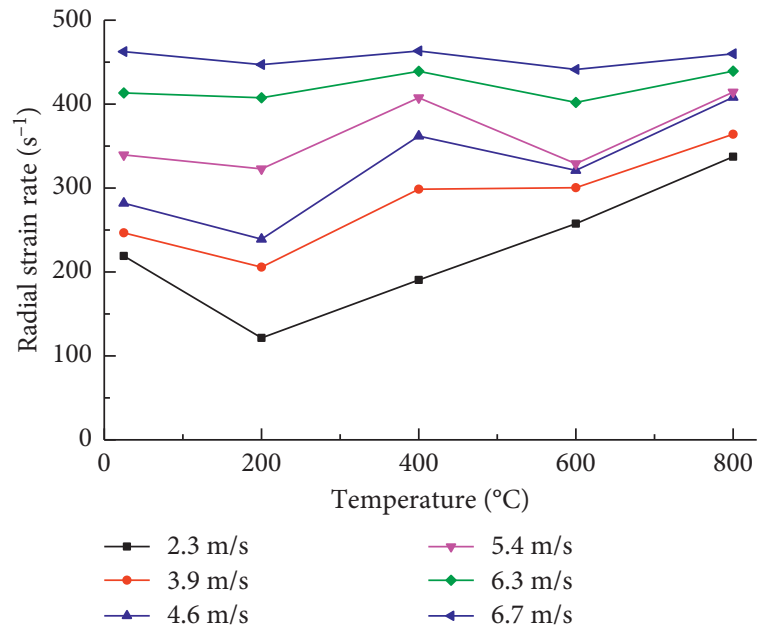

Figure 13: Variation of average strain rate with heating temperature.

strain rate is approximately $\pm 48 \%$ at a striker velocity of $2.3 \mathrm{~m} / \mathrm{s}$ and approximately $\pm 3 \%$ at a striker velocity of $6.7 \mathrm{~m} /$ s. Therefore, temperature has a large effect on the average strain rate at low striker velocity and a small effect on the average strain rate at high striker velocity. Therefore, the influence of temperature on average strain rate is weakened as the striker velocity increases.

\subsection{Failure Modes of High-Temperature Sandstone Specimens} in Dynamic Splitting Tensile Tests. Under the six kinds of striker velocities, the failure modes of high-temperature sandstone specimens at $25^{\circ} \mathrm{C}-800^{\circ} \mathrm{C}$ are presented in Table 4 . The left side of the sandstone specimen is in contact with the input bar, whereas the right side is in contact with the output bar.

As presented in Table 4, under six kinds of striker velocities, the high-temperature sandstone specimens are split into two roughly equal semicylinders along the radial loading direction. Meanwhile, two local crushing zones emerge in the sandstone specimens at the contact positions with the input and output bars. Moreover, the local crushing zone near the input bar is slightly larger than that near the output bar.

At the same temperature, striker velocity influences the failure modes. When the striker velocity is small, the sandstone specimens are split into two approximately complete semicylinders with very small local crushing zones. As the striker velocity increases, the size of the local crushing zone gradually increases. Additional fractures appear on one of the two semicylinders, which lead to the high breakage degree and formation of small fragments.

Under the same striker velocity, the breakage degree of two semicylinders varies as the heating temperature increases. When the striker velocity is $2.3 \mathrm{~m} / \mathrm{s}$, the sandstone specimens are split into two approximately complete semicylinders, and the temperature shows little influence on the splitting failure mode. However, when the striker velocity exceeds $2.3 \mathrm{~m} / \mathrm{s}$ and the temperature ranges from $200^{\circ} \mathrm{C}$ to $800^{\circ} \mathrm{C}$, the breakage degree of sandstone specimens increases with the growth of heating temperature. The breakage degrees at $200^{\circ} \mathrm{C}$ and $400^{\circ} \mathrm{C}$ are less than that at $25^{\circ} \mathrm{C}$, whereas those at $600^{\circ} \mathrm{C}$ and $800^{\circ} \mathrm{C}$ are higher than that at $25^{\circ} \mathrm{C}$.

The dynamic splitting failure mode of high-temperature sandstone specimens is relatively complex due to the coupling effect of high temperature and impact load. Under impact load, disordered microcracks in sandstones propagate in an orderly manner, and those in the center of the sandstone specimen initiate and grow quickly along the loading direction. Subsequently, the main crack along the radial direction is formed through the sandstone specimens. As the striker velocity increases, the force applied on the sandstone specimens sharply increases. Before the main crack is formed through high-temperature sandstone specimens, local crushing zones occur at its contact positions with the input and output bars due to the greater compressive stress than the compressive strength. Given that the impact loading rate is considerably higher than the propagation speed of the splitting crack, two semicylinders can still contact with the input and output bars. Hence, continuous loading leads to compression crushing at the two ends of the semicylinders.

When the temperature rises from $25^{\circ} \mathrm{C}$ to $200^{\circ} \mathrm{C}$, the water in the sandstone specimens evaporates, micropores close, and the microstructure becomes dense due to thermal expansion. When the temperature rises from $400^{\circ} \mathrm{C}$ to $800^{\circ} \mathrm{C}$, physical and chemical changes occur in the minerals in the sandstone. The size of the micropores in the sandstone specimens increases, and some cracks appear. As the heating temperature increases, the damage in the sandstone increases due to the growth and coalescence of internal microcracks. Hence, the bearing capacity and tensile strength are decreased, and brittleness is also weakened.

As presented in Table 4, the color of the sandstone specimens changes at high temperature. At $25^{\circ} \mathrm{C}$, the sandstone specimens are gray. At $200^{\circ} \mathrm{C}$ and $400^{\circ} \mathrm{C}$, the gray color of the sandstone specimens is deeper than that at $25^{\circ} \mathrm{C}$, whereas at $600^{\circ} \mathrm{C}$ and $800^{\circ} \mathrm{C}$, it turns gray white. The color of the high-temperature sandstone specimens is the lightest at $800^{\circ} \mathrm{C}$. 


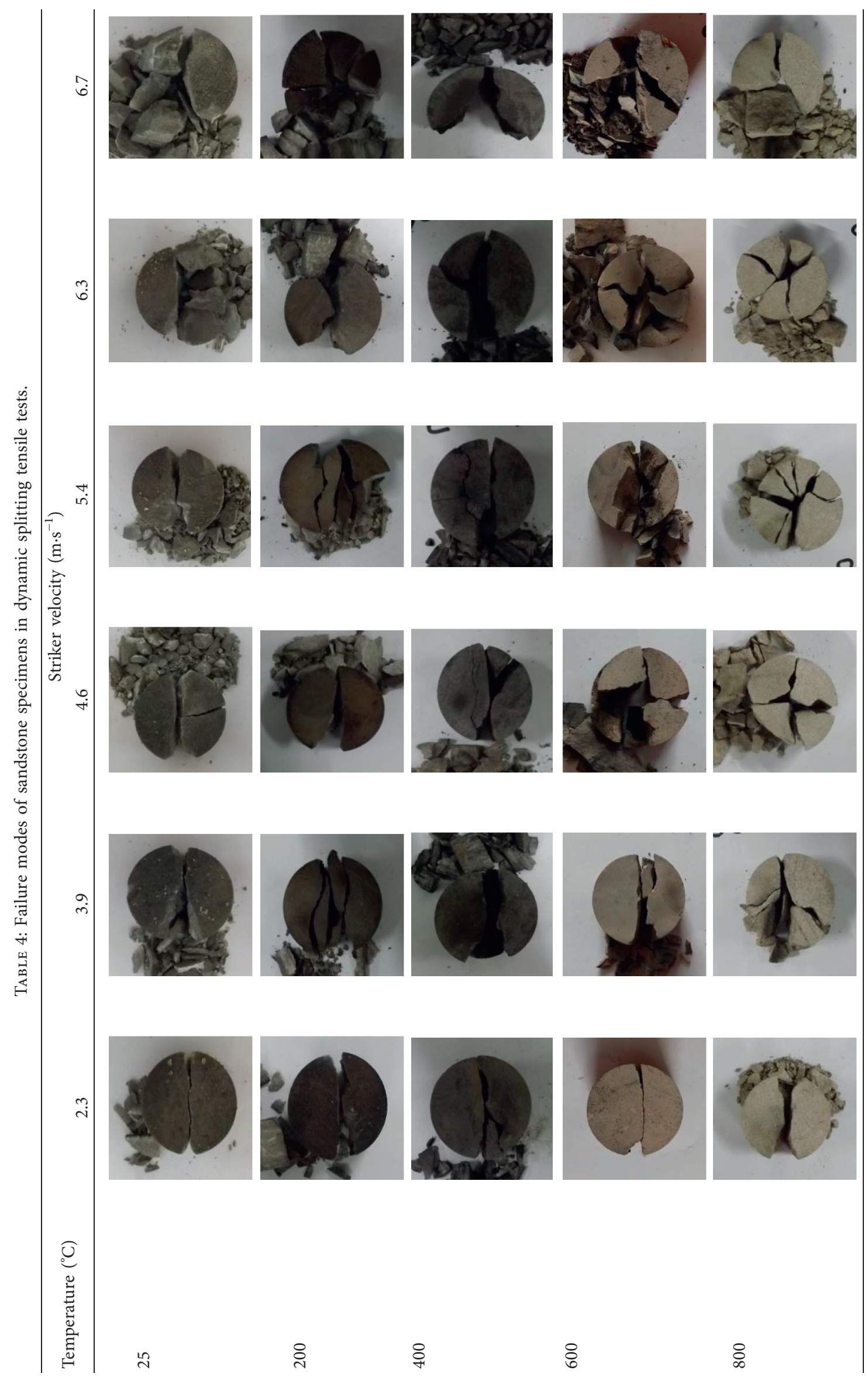




\section{Conclusions}

To investigate the dynamic splitting tensile characteristics of sandstones at actual high temperatures, dynamic splitting tensile tests were conducted on sandstone specimens at different actual high temperatures and loading rates by using SHPB device and high-temperature environment box. The effects of loading rate and high temperature on the dynamic stress-strain curves, tensile strength, deformation, and failure mode were also discussed. The major conclusions are as follows:

(1) Before the peak points, dynamic tensile stress-strain curves gently increase at $25^{\circ} \mathrm{C}$, when the heating temperature is higher than $200^{\circ} \mathrm{C}$. The brittleness of sandstone specimens is enhanced at $200^{\circ} \mathrm{C}$ and $400^{\circ} \mathrm{C}$, but slight ductility is observed at $600^{\circ} \mathrm{C}$ and $800^{\circ} \mathrm{C}$.

(2) Dynamic tensile strength increases in a power function with average strain rate, and the strain rate effect of dynamic tensile strength is closely related to temperature. When the striker velocity exceeds $2.3 \mathrm{~m} / \mathrm{s}$, the dynamic radial strain first decreases and then increases with the rising temperature. A quadratic polynomial relation exists between dynamic radial strain and heating temperature.

(3) The average strain rate first decreases and then increases with the rising temperature. The temperature effect on the average strain rate is strong at low striker velocity and weak at high striker velocity. Under the same temperature, the strain rate increases in a quadratic polynomial function with the growth of the striker velocity.

(4) In dynamic splitting tensile tests, high-temperature sandstone specimens are split into two semicylinders along the radial loading direction. Moreover, two local crushing zones appear at the contact positions with the input and output bars; the local crushing zone near the input bar is slightly larger than that near the output bar. The temperature effect on failure mode is weak at low striker velocity and strong at high striker velocity.

In this study, the dynamic tensile characteristics of rocks at actual high temperatures are investigated using the SHPB test device. This research provides references for the stability analysis of surrounding rocks in the blasting excavation process. Given the limited types of rock samples used, the dissolution law of other types of rock will be studied in future works.

\section{Data Availability}

The datasets generated and analyzed in the current study may be obtained from the corresponding author upon reasonable request.

\section{Conflicts of Interest}

The authors declare no conflicts of interest regarding the publication of this paper.

\section{Acknowledgments}

This research was funded by the National Natural Science Foundation of China (no. 51674008), Anhui Natural Science Foundation (nos. 1808085ME134, 1808085QE148, and 2008085QE220), project funded by China Postdoctoral Science Foundation (no. 2018M642504), Anhui Postdoctoral Science Foundation (no. 2015B058), and Quality Engineering Project of Anhui Province (no. 2016jyxm0283).

\section{References}

[1] C.-P. Lu, L.-M. Dou, N. Zhang et al., "Microseismic frequency-spectrum evolutionary rule of rockburst triggered by roof fall," International Journal of Rock Mechanics and Mining Sciences, vol. 64, pp. 6-16, 2013.

[2] C.-P. Lu, G.-J. Liu, Y. Liu, N. Zhang, J.-H. Xue, and L. Zhang, "Microseismic multi-parameter characteristics of rockburst hazard induced by hard roof fall and high stress concentration," International Journal of Rock Mechanics and Mining Sciences, vol. 76, pp. 18-32, 2015.

[3] C.-P. Lu, Y. Liu, H.-Y. Wang, and P.-F. Liu, "Microseismic signals of double-layer hard and thick igneous strata separation and fracturing," International Journal of Coal Geology, vol. 160-161, pp. 28-41, 2016.

[4] D. Ma, J. Wang, and Z. Li, "Effect of particle erosion on mining-induced water inrush hazard of karst collapse pillar," Environmental Science and Pollution Research, vol. 26, no. 19, pp. 19719-19728, 2019.

[5] D. Ma, H. Y. Duan, W. T. Liu, X. T. Ma, and M. Tao, "Water-sediment two-phase flow inrush hazard in rock fractures of overburden strata during coal mining," Mine Water and the Environment, vol. 39, pp. 308-319, 2020.

[6] M. C. He and P. Y. Guo, "Deep rock mass thermodynamic effect and temperature control measures," Chinese Journal of Rock Mechanics and Engineering, vol. 32, no. 12, pp. 23772393, 2013.

[7] W. R. Alexander, H. M. Reijonen, and I. G. McKinley, "Natural analogues: studies of geological processes relevant to radioactive waste disposal in deep geological repositories," Swiss Journal of Geosciences, vol. 108, no. 1, pp. 75-100, 2015.

[8] S. Cloetingh, J.-D. Van Wees, and V. Wesztergom, "Thermomechanical controls on geothermal energy resources: case studies in the Pannonian Basin and other natural laboratories," Acta Geodaetica et Geophysica, vol. 52, no. 2, pp. 157160, 2017.

[9] L. X. Xiong and L. J. Yu, "Advances of mechanical properties of rock under high temperature and after high temperature," Journal of Geological Hazards and Environment Preservation, vol. 29, no. 1, pp. 76-82, 2018.

[10] H. Tian, T. Kempka, S. Yu, and M. Ziegler, "Mechanical properties of sandstones exposed to high temperature," Rock Mechanics and Rock Engineering, vol. 49, no. 1, pp. 321-327, 2016.

[11] D. Ma, J. J. Wang, X. Cai et al., "Effects of height/diameter ratio on failure and damage properties of granite under coupled bending and splitting deformation," Engineering Fracture Mechanics, vol. 220, Article ID 106640, 14 pages, 2019.

[12] J. Shang, S. R. Hencher, and L. J. West, "Tensile strength of geological discontinuities including incipient bedding, rock joints and mineral veins," Rock Mechanics and Rock Engineering, vol. 49, no. 11, pp. 4213-4225, 2016. 
[13] Z. T. Bieniawski and I. Hawkes, "Suggested methods for determining tensile strength of rock materials," International Journal of Rock Mechanics and Mining Sciences, vol. 15, no. 3, pp. 99-103, 1978.

[14] S. Kahraman, M. Fener, and E. Kozman, "Predicting the compressive and tensile strength of rocks from indentation hardness index," Journal of the Southern African Institute of Mining and Metallurgy, vol. 112, pp. 331-339, 2012.

[15] P. A. Siratovich, M. C. Villeneuve, J. W. Cole, B. M. Kennedy, and F. Bégué, "Saturated heating and quenching of three crustal rocks and implications for thermal stimulation of permeability in geothermal reservoirs," International Journal of Rock Mechanics and Mining Sciences, vol. 80, pp. 265-280, 2015.

[16] N. N. Sirdesai, T. N. Singh, P. G. Ranjith, and R. Singh, "Effect of varied durations of thermal treatment on the tensile strength of red sandstone," Rock Mechanics and Rock Engineering, vol. 50, no. 1, pp. 205-213, 2017.

[17] Y. B. Chen, Y. Wang, and H. Luo, "Study on the Brazil split test of sandstone under different temperatures," Mining Research and Development, vol. 38, no. 8, pp. 45-50, 2018.

[18] T. Yin, P. Wang, X. Li, B. Wu, M. Tao, and R. Shu, "Determination of dynamic flexural tensile strength of thermally treated laurentian granite using semi-circular specimens," Rock Mechanics and Rock Engineering, vol. 49, no. 10, pp. 3887-3898, 2016.

[19] M. Liang, S. H. Zhang, and B. Shu, "Effect of different cooling ways on Brazilian tension characteristics of heat-treated granite," Journal of Water Resources and Water Engineering, vol. 29, no. 2, pp. 186-193, 2018.

[20] Z. Zhou, X. Cai, X. Li, W. Cao, and X. Du, "Dynamic response and energy evolution of sandstone under coupled static-dynamic compression: insights from experimental study into deep rock engineering applications," Rock Mechanics and Rock Engineering, vol. 53, no. 3, pp. 1305-1331, 2020.

[21] F.-Q. Gong, X.-F. Si, X.-B. Li, and S.-Y. Wang, "Dynamic triaxial compression tests on sandstone at high strain rates and low confining pressures with split Hopkinson pressure bar," International Journal of Rock Mechanics and Mining Sciences, vol. 113, pp. 211-219, 2019.

[22] J. R. Klepaczko and A. Brara, "An experimental method for dynamic tensile testing of concrete by spalling," International Journal of Impact Engineering, vol. 25, no. 4, pp. 387-409, 2001.

[23] H. Schuler, C. Mayrhofer, and K. Thoma, "Spall experiments for the measurement of the tensile strength and fracture energy of concrete at high strain rates," International Journal of Impact Engineering, vol. 32, no. 10, pp. 1635-1650, 2006.

[24] B. Erzar and P. Forquin, "An experimental method to determine the tensile strength of concrete at high rates of strain," Experimental Mechanics, vol. 50, no. 7, pp. 941-955, 2010.

[25] F.-Q. Gong and G.-F. Zhao, "Dynamic indirect tensile strength of sandstone under different loading rates," Rock Mechanics and Rock Engineering, vol. 47, no. 6, pp. 2271-2278, 2014.

[26] Y. X. Zhou, K. Xia, X. B. Li et al., "Suggested methods for determining the dynamic strength parameters and mode-I fracture toughness of rock materials," International Journal of Rock Mechanics and Mining Sciences, vol. 49, pp. 105-112, 2012.

[27] F. Dai, S. Huang, K. Xia, and Z. Tan, "Some fundamental issues in dynamic compression and tension tests of rocks using split Hopkinson pressure bar," Rock Mechanics and Rock Engineering, vol. 43, no. 6, pp. 657-666, 2010.
[28] Q. Ping, Q. Y. Ma, and P. Yuan, "Energy dissipation analysis of stone specimens in SHPB tensile test," Journal of Mining and Safety Engineering, vol. 30, no. 3, pp. 401-407, 2013.

[29] F. Gong and J. Hu, "Energy dissipation characteristic of red sandstone in the dynamic brazilian disc test with SHPB setup," Advances in Civil Engineering, vol. 2020, Article ID 7160937, 10 pages, 2020.

[30] Y. Zhao, H. Xiao, and Y. Huang, "Dynamic split tensile test of Brazilian disc of coal with split Hopkinson pressure bar loading," Journal of China Coal Society, vol. 39, no. 2, pp. 286-291, 2014.

[31] B. Du, H. Bai, Z. Ma, L. Ming, and G. Wu, "Experimental study on the dynamic tensile properties of red-sandstone after cyclic wetting and drying," Chinese Journal of Rock Mechanics and Engineering, vol. 37, no. 7, pp. 1671-1679, 2018.

[32] M. Wen, Z. Chen, J. Xu, W. Peng, and S. Lin, "Static-dynamic split tensile tests and micro analysis on red-sandstone with different moisture contents," Chinese Journal of Underground Space and Engineering, vol. 3, no. 1, pp. 86-92, 2017.

[33] M. Li, L. Qiao, and Q. Wen, "Energy dissipation of rock specimens under high strain rate with single joint in SHPB tensile tests," Chinese Journal of Geotechnical Engineering, vol. 19, no. 7, pp. 1336-1343, 2017.

[34] A. Mardoukhi, Y. Mardoukhi, M. Hokka, and V.-T. Kuokkala, "Effects of heat shock on the dynamic tensile behavior of granitic rocks," Rock Mechanics and Rock Engineering, vol. 50, no. 5, pp. 1171-1182, 2017.

[35] T. Yin, L. Bai, X. Li, X. Li, and S. Zhang, "Effect of thermal treatment on the mode I fracture toughness of granite under dynamic and static coupling load," Engineering Fracture Mechanics, vol. 199, pp. 143-158, 2018.

[36] S. Liu, J. Y. Xu, E. L. Bai, L. ZHI, and T. CHEN, "Experimental study of dynamic tensile behaviors of marble after high temperature," Rock and Soil Mechanics, vol. 34, no. 12, pp. 3500-3504, 2013.

[37] X.-Q. Wang, A. Schubnel, J. Fortin, Y. Guéguen, and H.-K. Ge, "Physical properties and brittle strength of thermally cracked granite under confinement," Journal of Geophysical Research: Solid Earth, vol. 118, no. 12, pp. 6099-6112, 2013.

[38] Q. Ping, Q. Y. Ma, and P. Yuan, "Sensitivity of time for stress equilibrium to wave impedance ratio with different rising times in SHPB tests," Chinese Journal of Rock Mechanics and Engineering, vol. 32, no. 10, pp. 2128-2134, 2013.

[39] P. Yuan, Q.-y. Ma, and D.-d. Ma, "Stress uniformity analyses on nonparallel end-surface rock specimen during loading process in SHPB tests," Advances in Civil Engineering, vol. 2018, Article ID 5406931, 12 pages, 2018.

[40] Q. Ping, Q. Y. Ma, and P. Yuan, "Stress equilibrium in rock specimen during the loading process of SHPB experiment," Explosion and Shock Waves, vol. 33, no. 6, pp. 655-661, 2013.

[41] K. Xia, J. Cheng, and S. Hu, "Application of SHPB apparatus to the measurement of high temperature dynamical mechanical behavior of materials," Journal of Experimental Mechanics, vol. 13, no. 3, pp. 307-313, 1998.

[42] K. Xia and W. Yao, "Dynamic rock tests using split Hopkinson (Kolsky) bar system-a review," Journal of Rock Mechanics and Geotechnical Engineering, vol. 7, no. 1, pp. 27-59, 2015.

[43] J. T. Gomez, A. Shukla, and A. Sharma, "Static and dynamic behavior of concrete and granite in tension with damage," Theoretical and Applied Fracture Mechanics, vol. 36, no. 1, pp. 37-49, 2001. 